\title{
Low Carbon Transition of Residential Electricity Consumption in Nigeria: A System Dynamics Modeling Approach
}

\author{
Babajide Epe Shari ${ }^{1, *}$, Yacouba Moumouni², Abiodun Suleiman Momodu ${ }^{3}$ \\ ${ }^{1}$ West African Science Service Centre on Climate Change and Adapted Land Use, Université Abdou Moumouni, Niamey, Niger \\ ${ }^{2}$ Electrical and Computer Engineering, Higher Colleges of Technology, Ras Al-Khaymah, United Arab Emirates \\ ${ }^{3}$ Centre for Energy Research and Development, Obafemi Awolowo University, Ile Ife, Nigeria
}

Email address:

babadjide.s@edu.wascal.org (B. E. Shari),ymoumouni@hct.ac.ae(Y. Moumouni), abiodunmomodu8@gmail.com (A. S. Momodu)

${ }^{*}$ Corresponding author

\section{To cite this article:}

Babajide Epe Shari, Yacouba Moumouni, Abiodun Suleiman Momodu. Low Carbon Transition of Residential Electricity Consumption in Nigeria: A System Dynamics Modeling Approach. International Journal of Energy and Power Engineering. Vol. 9, No. 1, 2020, pp. 11-21. doi: 10.11648/j.ijepe.20200901.12

Received: January 10, 2020 Accepted: January 31, 2020; Published: March 10, 2020

\begin{abstract}
It is imperative that Nigeria reduces wastage in residential electricity consumption and motivate energy saving behaviors through energy efficiency measures. These strategies aim to minimize frequent power sheds, which in turn increase reliability, thus benefiting the environment and electricity consumers. This article examines the effects of such innovative approaches to electricity savings in Nigeria through: 1) prepaid electricity metering systems and 2) fast replacements of inefficient and aging appliances. Relationships between residential electricity consumption, energy efficiency, and carbon footprint were also assessed vis-à-vis the replacement of old energy appliances and analogue electricity billing systems with more efficient devices and through prepaid metering systems, respectively. These techniques intend to promote energy saving behaviors. A System Dynamics model built on Stella platform, is used to analyze the implication of energy efficiency policy implementation on residential electricity consumption based on a simulation period of 41 years $(2010-2050)$. Secondary data were sourced from the Bureau of Statistics, published articles, Nigerian power sector, World Bank, and primary data using cross sectional surveys of residential electricity consumers. Results, not only revealed that availability and utilization of prepaid electric meters and efficient appliances would motivate electricity saving behaviors, but also showed that efficient technologies could be the main drivers to future energy savings. Results also showed that carbon emissions were cut down by $45 \%$ in 2050. In addition, changes in electricity tariffs did not have any consequential effect on electricity consumption, but would rather influence electricity demand. Also, large number of occupant per house might have a negative impact on the Nigerian economic growth. Finally, results suggest that subsidies should be used on new household appliances as an effective energy policy measures. The developed model can be replicated in similar sectors in other emerging economies.
\end{abstract}

Keywords: System Dynamics, Prepaid Meter, Energy Efficiency, Household Appliances, Electricity Consumption

\section{Introduction}

It is estimated that about 1.1 billion persons still lack access to modern energy globally [1]. Meeting the needs of these people for sustainable and efficient use of valuable energy resources are twin-like issues facing emerging economies. This backdrop could suggest the non-active participation of emerging economies in global transition to clean and low carbon energy systems. Thus, the success of meeting the aforementioned challenges would not only lead the way to affordable, reliable, and generally acceptable energy, but would also alleviate abject poverty by improving economic prosperity [2]. In addition, the success will curb any environmental issues resulting from growing carbon emissions by the emerging nations through, their geometric rising populations and rapid industrial growths [3].

Energy, in all its forms is a vital commodity for economic 
prosperity [4]. In its tertiary form as electricity, energy is a crucial part of modern life and important to various economic sectors, such as agriculture, health, education, industry, construction, and housing [5]. Various sectors consume electricity for different purposes, such as for heating, lighting, cooling, refrigeration, and operating electronics gadgets in order to achieve the objectives towards sustenance of life and economic development [6]. The four major economic sectors are: 1) residential - homes and apartments; 2) commercial - offices, malls, stores, schools, hospitals, hotels, warehouses, restaurants, places of worship and public assembly; 3) industrial - facilities and equipment used for manufacturing, agriculture, mining, and construction; and 4) transportation - vehicles that transport people or goods [7]. According to [8], twenty percent of the world energy is consumed by the residential sector. The energy consumed is in the form of lighting, cooling, refrigeration, heating, and operating electrical appliances [9] and [10]. However, energy sources from which electricity is derived are mostly not environmentally friendly. As a result, here is a global clamor for a major energy transition.

Worldwide, energy systems are transitioning to Renewable Energy (RE) due to a growing concern of depletion and environmental pollution of fossil fuel extraction, energy security and the volatility in crude oil prices [8]. Electricity situation underpinning this transition in the emerging economies is accompanied with various implications as a result of the deplorable state of the energy sector, which include electricity shortages, inconsistent policies etc. [11]. Energy transition is highly dependent on economic development, population growth, depletion of existing energy resources, change in technology and the increasing cost of electricity [4]. These factors are highly driven by the efficiency of electrical appliances [12].

Although, the Nigerian electricity sector still struggles to meet its supply-demand gap which is heavily dependent on fossil-fuel based resources [13, 11]. Despite this, the country is making efforts to go along with global community in supporting initiatives to reduce greenhouse gas (GHG) emissions. Such initiatives aimed at promoting the utilization of energy-efficient devices and increasing the shares of (RE) in the Nigerian energy mix [14]. These national efforts encompass enhancing the distribution system through use of prepaid metering infrastructures sand a reduction in analogue meters, which was a mere estimation billing scheme [15]. It is therefore, crucial to explore drivers of electricity consumption in the residential sector and propose innovative approaches to curtail excesses in residential electricity consumption. Achieving these goals would allow lawmakers, investors and authorities to set the proper policy measures in order to enhance the existing sustainable energy pathways and transition guidelines in Nigeria [16].

Interaction between variables of electricity consumption and consumption-efficiency are closely interrelated and exhibits complex behaviors, thereby require the use of more complex energy models [17] and [18]. As a result, this study adapts the use of a complex modeling approach to study the efficiency of residential electricity demand in its transition to support low carbon as panacea to energy security [19]. In as much as the transition process to low carbon will be a viable solution to the energy issues facing the Nigerian power sector [20], it, also, encourages the implementation of efficiency measures on customer premises [21]. The realization of these schemes has been slowed down due to policy inconsistencies; this was significantly marked by the 2005 Renewable Energy Master Plan (REMP) document $[11,14]$.

This article analyzes the influence of prepaid meter as against analogue meter, household $(\mathrm{HH})$ size and replacement of old electrical appliances as motivation for promoting energy efficiency and enhance energy conservation through reduced energy consumption at the $\mathrm{HH}$ sector. In addition, this study examines: 1) the effect of a large-scale application and efficient use of prepaid electric meters on the Nigerian residential sector, 2) the carbon footprint of individuals, and 3) how such behavioral changes (energy conservation) in the use of more efficient $\mathrm{HH}$ appliances would influence job opportunities. Secondary and primary data sets is used for analysis. For secondary data, sources include published journal articles, relevant agencies in the Nigerian power sector, various the World Bank reports [22], the International Energy Agency (IEA), Vision 2020 report, the federal government roadmap for power sector reform [23], while the primary data were sourced from cross-sectional surveys among $\mathrm{HH}$ electricity consumers across four out of six geopolitical zones in Nigeria, regarding the relationship between electricity consumption-efficiency activities. The surveys were conducted to observe the 1) self-report energy relevant behavior as an impact to replacement of regular analogue meters [24], 2) challenges, and 3) bureaucracy involved in securing new prepared meters. This study applies feedback principle in System Dynamics on the its objectives to develop a model in Stella Professional platform to simulate the complexities and behaviorial changes in the Nigeria power sector [25]. The study recognizes the very limited nature of data available to conduct the analysis, this buttresses the need for the robust feedback principle explore in SD model.

Prior to this study, several studies were found in literature including review journals on electricity consumptions, energy transition [26], and prepaid meter $[15,27]$. However, there is no single study found that has considered the approach of SD modeling on electricity consumption-efficiency, prepaid meter, carbon footprint, and motivation to save electricity (energy conservation). This study has the specificity to relate both feedbacks effects and endogenous and exogenous variables. Thereby, the study expresses an innovative and scientific bases that examine the significant and dynamic interrelation among analyzed variables. Consequently, valuable policy implications are suggested. 


\section{Methodology}

\subsection{Model Description}

The model structure has three segments: i) power sector, ii) economic/social sector, and iii) environmental sector, which all together feed the major variables employed in the model. The power sector represents the following subsegments: 1) household ( $\mathrm{HH})$ electricity consumption, 2) energy intensity, 3) motivation to save electricity, 4) prepaid meter, 5) efficient technology devices/kits, 6) electricity demand, and 7) electricity saved. The economic/social segment denotes: 1) job opportunity, 2) Gross Domestic Product (GDP), 3) income, and 4) government policy. Finally, the environmental segment represents the environmental impact measured by subsequent carbon footprints.

\subsubsection{The Concept of System Dynamics}

Application of System Dynamics Models (SDMs) in system modeling developed by Forrester in the 1950s was used for analysis purposes in the study. This is due to the ability of SD to analyze the dynamics of behavior of systems, as it is suitable and capable of capturing feedbacks and delays in the power sector [28]. SD has the modeling potential to capture a range of complex interaction between economic, social, and environmental factors [10]. In addition, SD has been used for different studies to conduct simulation for energy development, electricity demand forecast, and system planning; these simulations include estimates of carbon emissions in developed and emerging economies [2832]. SD modeling was also applied in business dynamics evaluation of the economic implication by [33], and applied into assessment of water resource management [34].

SD models employ the inner complexity and the various interactions between stocks, flows, and variable tools. Therefore, results obtained from simulated models were harnessed using feedback loops and delays between energy prices, energy resources, supply and demand and per capita to guide the decisions of policy makers and investors. Developed models also help lawmakers and utility companies to better understand the power sector in terms of: 1) advancing and anticipating generation capacity, 2) liberalizing the power sector, 3) analyzing supply and demand patterns, and 4) billing energy consumption [28].

Figure 1 shows a basic modeling structure of SD. It consists of three fundamental components - a stock, flow, and converter (auxiliary variable). The stock is either an accumulator or integration or a level that depicts the exponential growth of the system [35]. The flows (inflow and outflow) represent births and deaths, respectively according to Figure 1. These flows control the value and growth that occur in stocks with respect to the birth and death rate as auxiliary variables. Forrester regards converters as 'goals' that serve to transmit information into a system under study via Stella or iThink modeling plateform [35]. Mathematically, the model shown in Figure 1 represents a first-order non-linear dynamic system.

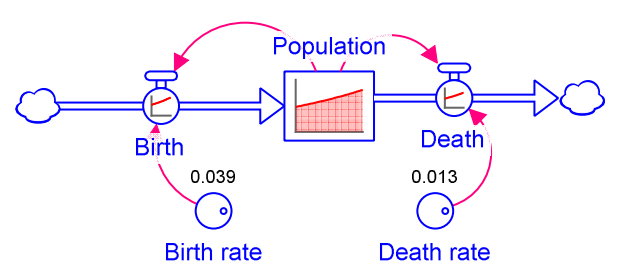

Figure 1. A typical stock and flow diagram for population model.

This type of systems behavior cannot be predicted by mere studying the stock and flow diagram or underlying equations of the model $[36,37]$. The complexity that occurs from the interactions between the stock and flows is important. These interactions cause the complexity of the system to rapidly increase as the number of stocks increases [37]. This understanding is what underlies modeling principle of SD which in turn not only informs the modeling approach employed in this study but also guides its structure.

\subsubsection{The Study Conceptual Framework}

Sterman and Forrester outlined four basic steps are involved in creating an SDM. These steps are: i. conceptualization; ii. formulation; iii. testing; and iv. implementation [38, 39]. Conceptualization of a problem is the first step involved in model building process and the most important activity in the development of a system dynamics model [40]. The conceptualization of SD model considering set of steps, which must be determined during the conceptualization process was described [39]. Accordingly, a well conceptualized model should address the following: (1) purpose of the model; (2) model boundary by identifying key variables; (3) description of the behavior by drawing a reference mode of key variables; and (4) diagram of basic mechanism to outline feedback loop of the system under study [41]. These approaches would form the basis of conceptualizing the modeling process of the study. The relevance of a conceptual model is in its capability to address germane reference modes (problem) in the system. This scheme is further explained with a Causal Loop Diagram (CLD) in Figure 2.

The CLD of the study, shows the structural explanations of variables' behavior and how they communicate with the dominant feedback loops within the model. The CLD is helpful in providing an overview of the relative complex simulation model [42]. The CLD also shows the social, economic and environmental components suggesting sustainability of feedback loops vis-à-vis the power sector. The setup helps explain the Residential Electricity Consumption - Efficiency (RECE). The CLD has three reinforcing loops (R) and three balancing loops (B). Polarities (+/-) are indicated on feedback arrows. A positive sign indicates incremental growth, while negative sign suggests declined/reduced relation between connecting variables.

B1: Efficient technology kits, Motivation to save, Energy intensity, HH consumption, GDP, Energy demand, Price of efficiency tech, Efficient technology kits.

B2: HH consumption, Electricity saved, GDP, Income, HH 
consumption.

B3: HH consumption, Electricity saved, Job opportunity, Income, $\mathrm{HH}$ consumption.

R1: Electricity saved, GDP, Electricity Demand, Electricity Saved.

R2: Electricity saved, Job opportunity, income, Electricity demand, electricity saved.

R3: electricity saved, GDP, Income, Demand, electricity saved.

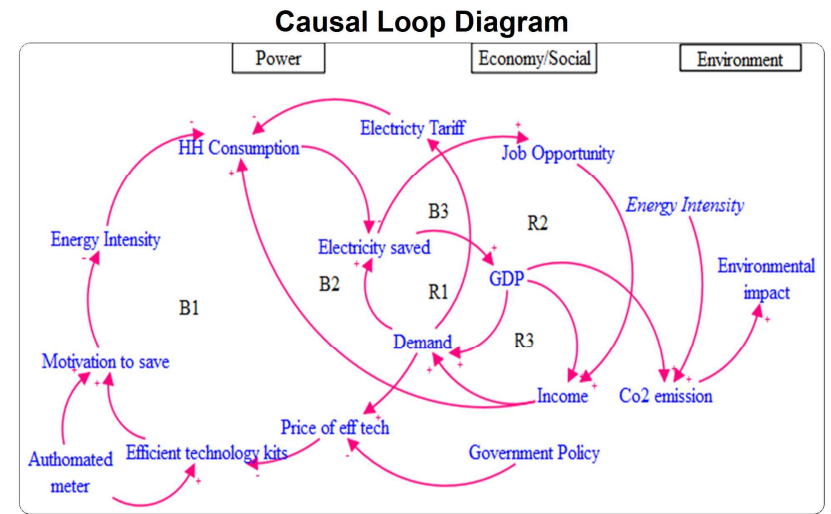

Figure 2. Causal Loop Diagram for the Sustainable Residential Electricity Consumption-efficiency.

\subsubsection{Establishment of the SD Model - Model Design}

SDM method offers reasonable means of representing the driving forces for the residential electricity consumptionefficiency [18]. Model design is represented by a stock and flow diagram (SFD). The model is organized according to the structure reflected by the CLD. GDP is considered as an exogenous parameter for determination of income dynamics [26] and [43]. The year 2010 was utilized as the base year data for the model, whereby the residential electricity consumption, population, and carbon footprint were obtained from the Nigerian Power Sector (NPS), National Bureau of
Statistics (NBS) and International Energy Agency (IEA), respectively.

Figure 3 shows the simulated SD model of residential electricity consumption-efficiency. This was built using characteristics of the Nigerian household sector based on Stella professional platform [43]. The model is composed of five level variables (stocks), five rate variables (inflows) and 22 auxiliary variables, all with a year time step. The simulation period extends from 2010 to 2050, with 2010 chosen as a benchmark for the model. Hence, data from 2010 to 2016 were used for model validation purposes and 2017 to 2050 represent the simulation forecast period of the model.

Figure 3 also illustrates the Stock-flow diagram (SDM) for the SD model of residential electricity consumptionefficiency. The model structure is designed considering the aforementioned three basic segments, i.e., 1) power sector; 2) economy \& social; and 3) environmental segment, as shown in the CLD. In the power segment, the main stocks in the model are the residential/household (HH) electricity consumption. The $\mathrm{HH}$ electricity consumption is characterized by the intensity of the energy, types of kits, analogue meter, prepaid meter, motivation to save energy, and household size. The $\mathrm{HH}$ electricity consumption serves as the main motivation determining the amount of electricity saved. The efficiency component is implemented by replacing old electrical appliances with new ones - light bulbs, electric appliances, water pumping devices and air conditioners. the new appliances' efficiency is modelled, assuming the "goal seeking" behavior the latter scheme may be a good assumption, considering a diminishing return of efforts, time to reach this goal, and motivation to use new appliances as represented in technology advancement. The graph tool on tool bar in Stella platform is employed to represent its behavior.

\section{Household Electricity Consumption-Efficiency Model}

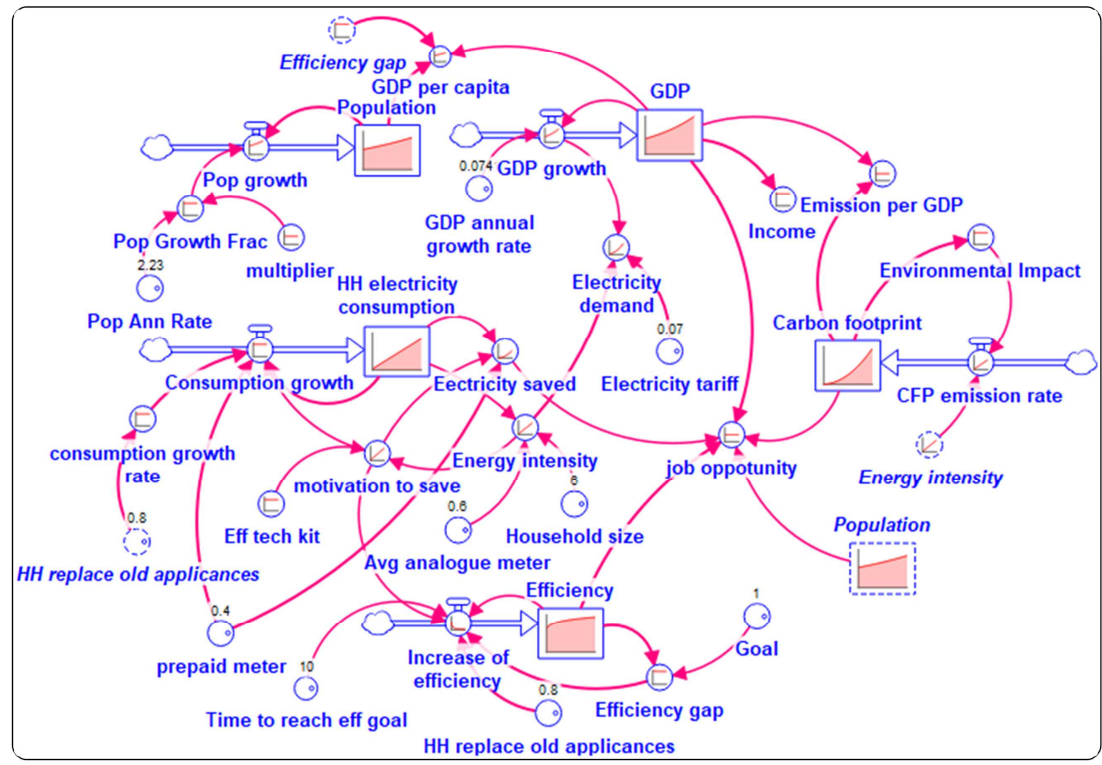

Figure 3. Stock-flow diagram (SFM) for the SD model of residential electricity consumption-efficiency. 
Variable types, notations and nomenclatures as used in the SFD, are listed in Table 1. Simulation differential equations in the SFD are defined based on the actual data for residential electricity consumption-efficiency in the base year (2010).

Table 1. Mathematical notations and nomenclatures of SD-SFD.

\begin{tabular}{|c|c|c|c|}
\hline Variable Type & Notation & Nomenclature & Unit \\
\hline \multirow{5}{*}{ Level } & $\mathrm{P}$ & Population & Million people \\
\hline & HHEC & Household electricity consumption & TWh \\
\hline & E & Efficiency & $\%$ \\
\hline & GDP & Gross Domestic Product & US Dollars \\
\hline & CFP & Carbon Footprint & Mtce \\
\hline \multirow{5}{*}{ Rate } & PG & Population growth & People/years \\
\hline & CG & Consumption growth & TWh/years \\
\hline & IE & Increase of Efficiency & $\% /$ year \\
\hline & CER & CFP emission rate & Mtce/year \\
\hline & GG & GDP growth & USD/year \\
\hline \multirow{22}{*}{ Auxiliary } & PGF & Population Growth Fraction & per year \\
\hline & PAR & Population Annual rate & $\%$ \\
\hline & GC & GDP per Capita & USD/person \\
\hline & GAGR & GDP Annual Growth rate & per year \\
\hline & IE & Income & USD \\
\hline & EPG & Emission per GDP & Mtce/USD \\
\hline & EI & Environmental Impact & _ \\
\hline & JP & Job opportunity & $\mathrm{Wh} / \mathrm{USD} /$ Person \\
\hline & ES & Electricity Saved & TWh \\
\hline & EI & Energy Intensity & TWh/Household \\
\hline & HHEC & Household size & People \\
\hline & AAM & Avg. Analogue meter & \\
\hline & ET & Electricity Tariff & $\overline{\mathrm{USD}} / \mathrm{kWh}$ \\
\hline & MS & Motivation to save & _ \\
\hline & ETK & Efficiency tech. kit & - \\
\hline & CGR & Consumption growth rate & per year \\
\hline & PM & Prepaid meter & 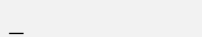 \\
\hline & TG & Time to reach goal & Years \\
\hline & HHROA & $\mathrm{HH}$ replacement of old appliance & $\%$ \\
\hline & EG & Efficiency gap & _ \\
\hline & $\mathrm{G}$ & Goal & _ \\
\hline & CGR & Consumption growth rate & per year \\
\hline
\end{tabular}

\subsection{Model Validation}

The model was validated using structure and behavioral test [1]. Data from the actual electricity consumption per capita and the modelled/calculated results were compared as seen in Figure 4. An estimate value of $22.9 \%$ error of deviation was obtained between the modeled and actual electricity consumption per capita. Thus, modeled data showed a wider and greater exponential trend compared to the actual data of electricity consumption per capita. This could be explained not only by an increase in the number of electrical appliances engaged in the model, but also due to the model structure, took into consideration outflows and variables that might serve as "goal seekers" at the consumption level (stock). Also, electricity self-generated accounts for the disparity in values.

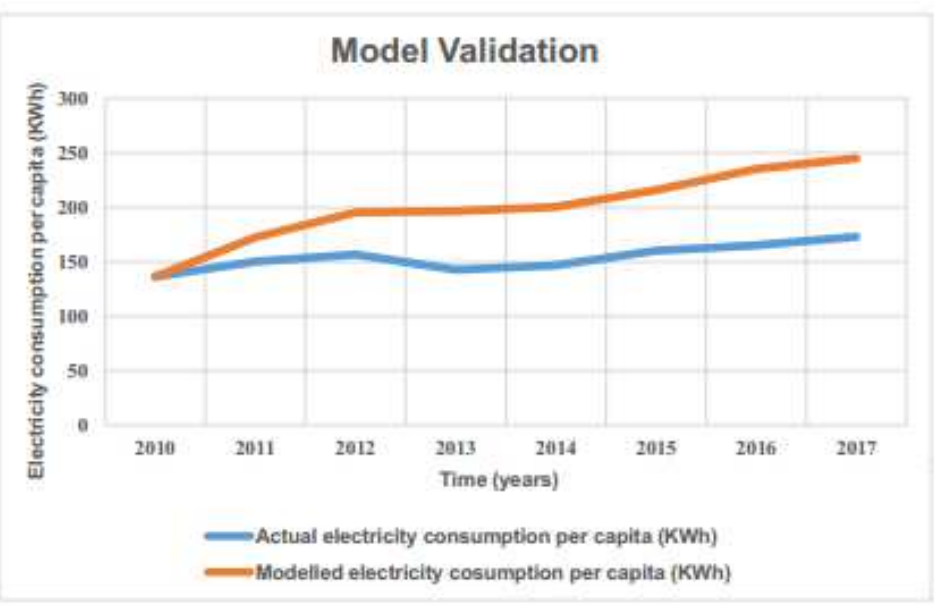

Figure 4. Household Electricity consumption per capita modeled - Household Electricity consumption per capita actual. 


\section{Results, Discussions, and Sensitivity Analysis (SA)}

SD models provide a scientific basis for designing sensitivity analysis of simulation models (iseesystems, 2019). Sensitivity analysis impacts were designed to evaluate the robustness of results obtained from the model, thereby, obtaining the most sensitive component of the model (Zheng et al., 2014). The study, therefore, employs the robust capability of SDM in Stella platform for sensitivity analysis of the residential electricity consumption-efficiency in the Nigerian Power Sector (NPS). SA were developed considering the following variables: (i) prepaid meter; (ii) household size; (iii) replacement of old appliances with efficient and newer ones; and (vi) electricity tariff. The impact would be assessed considering changes that are observed on the following: (1) household electricity consumption; (2) efficiency; (3) carbon footprint; and (4) job opportunity. Variables considered for SA were varied over specific sensitive trends and ranges within realistic values.

\subsection{Sensitivity Analysis for Prepaid Meters (PMs)}

SA for prepaid meter (PM) was done with the assumption that PM were made available to residents at a range of $0.2-$ 1.0 , i.e., $20 \%$ to $100 \%$. Five runs are specified in Table 2 considering sensitive range of values at an incremental distribution of 0.2 in Stella platform.

Table 2. Sensitivity values for prepaid meters.

\begin{tabular}{ll}
\hline Run & Value \\
\hline 1 & 0.2 \\
2 & 0.4 \\
3 & 0.6 \\
4 & 0.8 \\
5 & 1.0 \\
\hline
\end{tabular}

\subsubsection{Effects of PMs SA on Household Electricity Consumption (HHEC)}

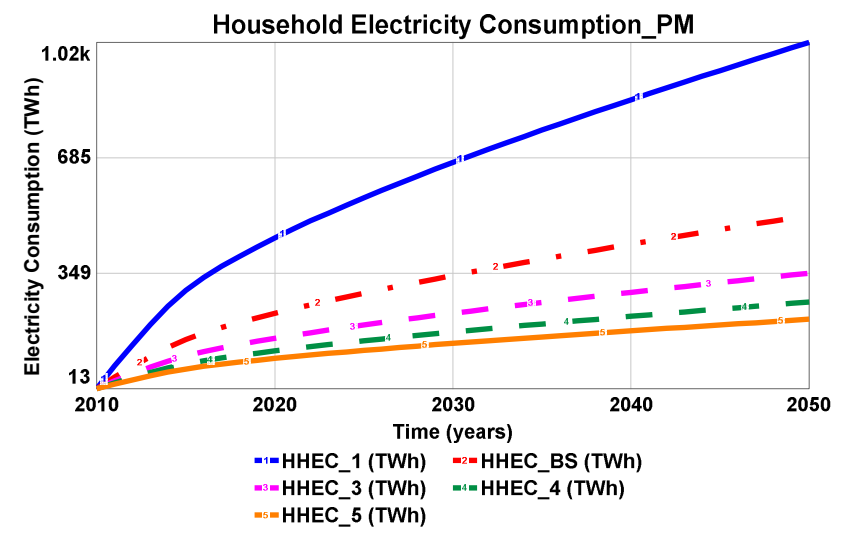

Figure 5. Household Electricity Consumption (TWh) at varied prepaid meter.

Figure 5 shows the SA of the HHEC in five different runs according to the values indicated in Table 2. The analysis, presented in Figure 5, illustrates that more deployment of prepaid meter to residents in Nigeria would reduce residential electricity consumption by about $75 \%$ at the end of 2050 , as observed in trend HHEC_5_BS at sensitivity value of 1.0 . This fact is further shown in the trends HHEC_3, and HHEC_ 4 as they compare to trend HHEC_2_BS the base scenario at sensitivity value of 0.4 .

\subsubsection{Effects of PMs SA on Household Electricity Saving Efficiency (ESE)}

Figure 6 shows influence of PM SA on ESE in five different runs according to the values indicated in Table 2. The analysis as shown in Figure 6 illustrates that availability and usage of prepaid meters for electricity billing in the Nigerian residential sector would improve consumer behavior towards electricity savings, thereby improving the share of electricity saved and available for other users since the NPS still struggles to meet electricity demand. Moreover, sensitivity value of 1.0 illustrated in run ESE_1 showed that consumer would conserve electricity when they use prepaid meter. Runs ESE_5, ESE_4, and ESE_3 confirmed and followed the similar trend observed in ESE_1. Run ESE_2_BS was set as base scenario.

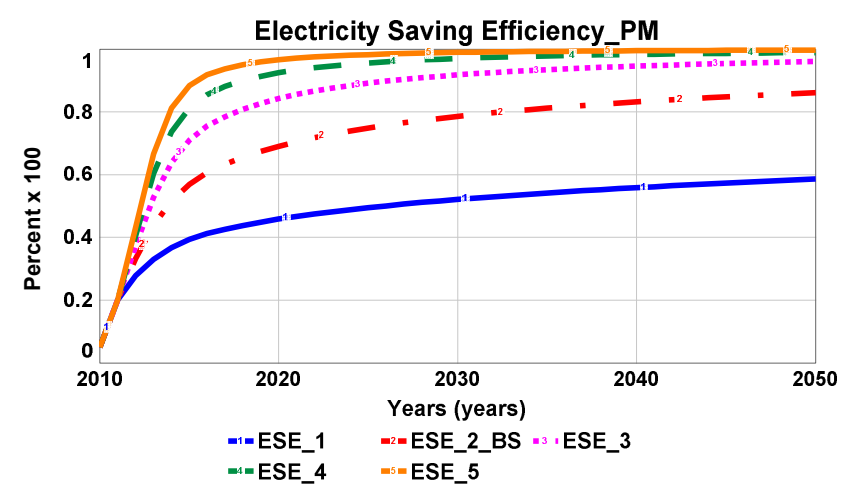

Figure 6. Electricity saving efficiency at varied prepaid meter.

\subsubsection{Effects of PMs SA on Carbon Footprint (CFP)}

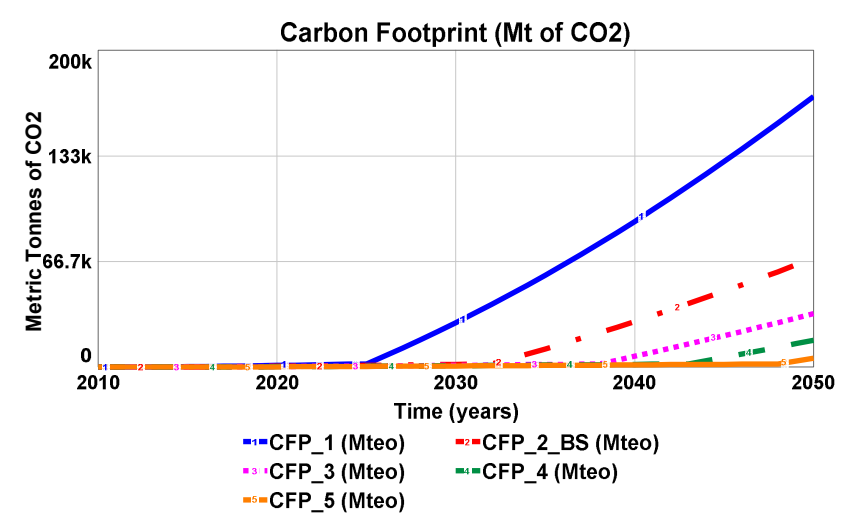

Figure 7. Carbon footprint at varied prepaid meter.

Figure 7 shows the impacts of PM on CFP in five different runs in accordance to table 2. Simulation reports shown in 
Figure 7 illustrates the availability and usage of prepaid meters for electricity billing in the Nigerian housing system. These impacts would decrease the amount of carbon emissions by about $65 \%$ in the horizon of 2050 . This could be seen in trends of CFP_5, CFP_ 4 and CFP 3 compared to the base scenario of $\overline{C F P} 2$ _BS. Although, in the first decade, 2010 - 2020, carbon cut was not observable compared to later decades, this could be caused by gradual accumulation of carbon in the atmosphere due to other exogenous factors.

\subsubsection{Effects of PMs SA on Job Opportunity (JO)}

Figure 8 shows the impacts of PMs SA on JO in the same five different runs stated in Table 2 . The simulated outputs, as illustrated in Figure 8, displayed a counterintuitive effect on the availability and usage of prepaid meters for electricity billing in the Nigerian housing sector. The number of employees is reduced. This is captured in the study as a reduction in energy consumed per US Dollar per person. This could also be a result of re-structuring in the NPS such that the Distribution Company (DISCO's) officials would implement a thorough defaulter check per house. Consequently, in the advent of the availability and usage of prepaid meters, such workers might be laid off or be engage in other administrative (if educated) activities.

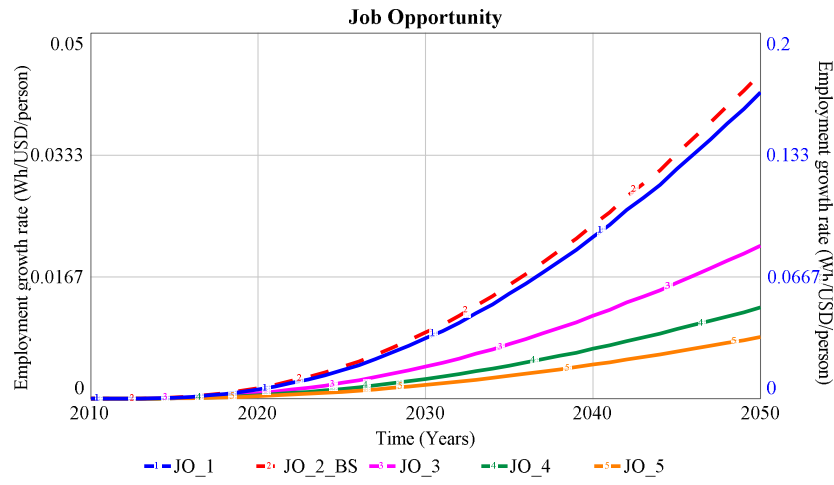

Figure 8. Job Opportunity at varied prepaid meter.

\subsection{Sensitivity Analysis for Usage of Efficient Electric Appliances (SA-EA)}

SA of electrical appliance was done with the assumption that efficient appliances were available for use to residents. The rate of availability ranges from 0.8 to 8.0. A total of five different runs are specified in Table 3 , considering sensitive range of values at an incremental distribution of 1.8 in Stella platform.

Table 3. Sensitivity analysis values for usage of efficient electric appliances.

\begin{tabular}{ll}
\hline Run & Value \\
\hline 1 & 0.8 \\
2 & 2.6 \\
3 & 4.4 \\
4 & 6.2 \\
5 & 8.0 \\
\hline
\end{tabular}

\subsubsection{Effect of SA-EA on Household Electricity Consumption (HHEC)}

Figure 9 shows SA of Household Electricity Consumption (HHEC) in five different runs in accordance to the values indicated in Table 3. This SA shows that utilizing more efficient appliances in the Nigerian household sector would result in a significant reduction of electricity consumption. The electricity saved could then be made available to regions with low electrification rate. This reduction can be seen in trends HHEC_EA3, HHEC_EA4, and HHE_EA5 compared to HHEC_2_BS, representing the base scenario. Thus, the use of more efficient residential appliance would show positive trend in motivating electricity saving behavior among users.

Similar principle illustrated in Figure 9 holds for Figure 10. Figure 10 therefore reaffirms that the usage of more efficient appliances among residents would motivate energy conservation.

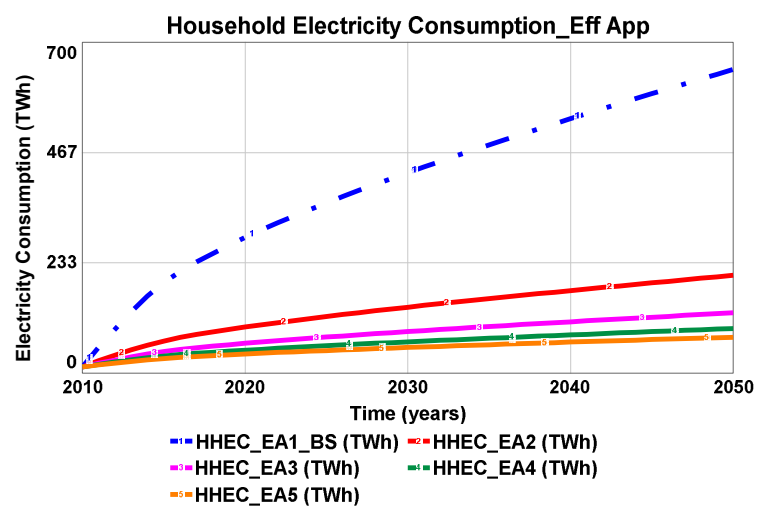

Figure 9. Household Electricity Consumption varied by efficient appliances.

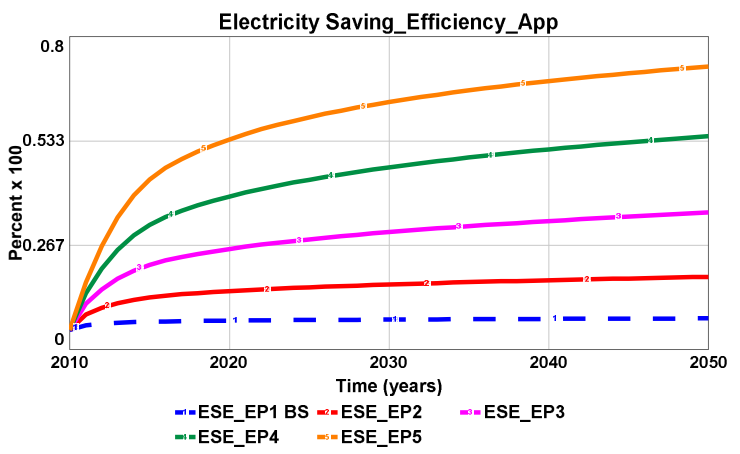

Figure 10. Electricity Saving Efficiency varied by efficient appliances.

\subsubsection{Effect of $\mathrm{SA}-\mathrm{EA}$ on Carbon Footprint (Mtoe of $\mathrm{CO}_{2}$ )}

Consequently, results shown in Figure 11 ascertain the effect and response of energy saving actions, such as use of prepaid electric meters in billing system and availability of more efficient appliances. From this backdrop, carbon saving principles agree favorably with energy saving techniques illustrated earlier. Figure 11, consequently, confirms that using more efficient appliances would tremendously cut down anthropogenic carbon emissions. 


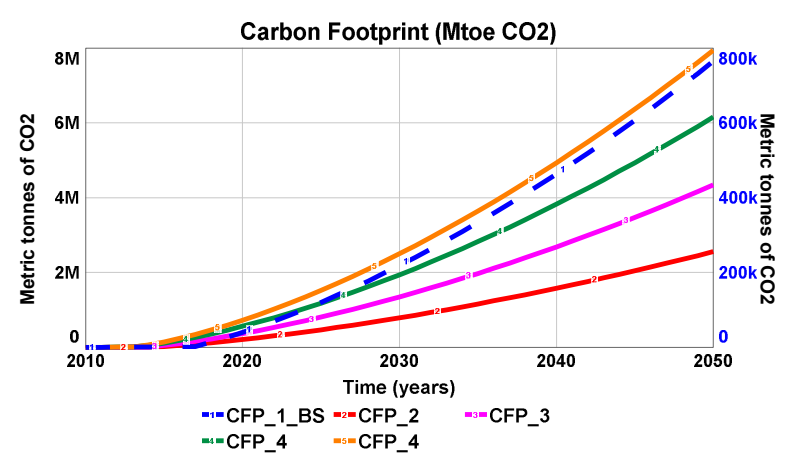

Figure 11. Carbon Footprint varied by efficient appliances.

\subsection{Sensitivity Analysis for Household size (SA-HH)}

The study carried out an extreme SA on normal household, considering a simulated size ranging from 5 to 9 individuals. In total, five runs were specified, as displayed in Table 4, with a unit incremental distribution in Stella platform as preferred. This normal increment turned out to output good results.

Table 4. Sensitivity runs of Household size.

\begin{tabular}{ll}
\hline Run & Value \\
\hline 1 & 5 \\
2 & 6 \\
3 & 7 \\
4 & 8 \\
5 & 9 \\
\hline
\end{tabular}

\subsubsection{Effect of HH SA on Household Electricity Consumption (HHEC)}

Figure 12 illustrates the SA of Household Electricity Consumption (HHEC) in five different runs according to the values indicated in Table 4. Analysis of Figure 12 shows positive correlations between number of household size and electricity consumption. HHEC_HH5 shows the greatest trend among all the five scenarios of Household electricity consumption; the size of the household was simulated to be nine (9). In contrast, HHEC_HH1 indicates the lowest trend of Household electricity consumption with five (5) individuals compared to six (6) inhabitants per house in the base scenario, i.e., HHEC_HH2 BS. The economic implications of this is further analyzed in Figure 13.

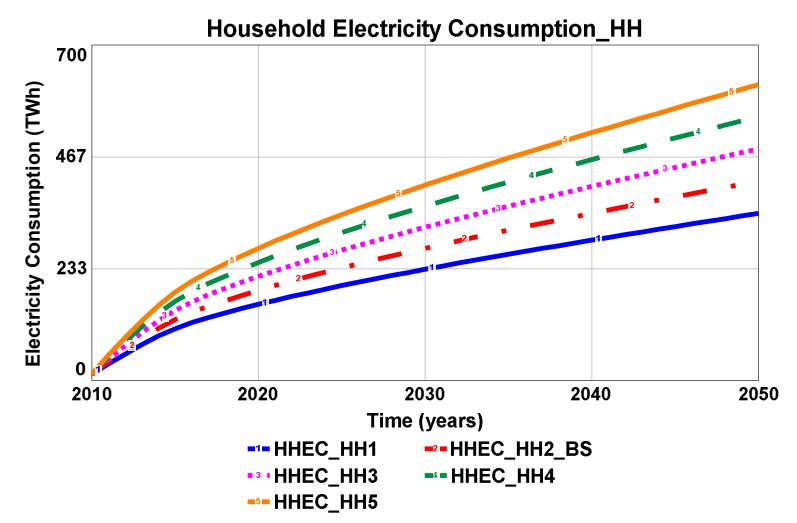

Figure 12. Household electricity consumption varied by Household size.

\subsubsection{Effect of HH SA on Economic Growth Considering Household Size}

Figure 13 illustrates the economic implications based on SA of the five sceneries from table 4. ECO 1 represents the trend with the lowest household size of five (5), while ECO_5 has nine (9) inhabitants per house and obviously unveiled the highest household size. Consequently, ECO_1 shows the most improved economic growth scenario among all the different runs. In contrast, trend ECO 5 indicates the lowest economic growth scenario. These results could suggest that a large number of occupants per house would continue to have a negative impact on the economic growth of Nigeria as a whole from the view point of GDP per capita. As electricity consumers increase with no subsequent improvement in the power system, the status quo will remain. Consequently, Figure 13 also reaffirms that electricity consumption is directly linked to economic growth. This condition suggests that electricity demand from the NPS is largely unmet. This further explains reasons for energy insecurity in the NPS, thus evidencing the country's low electricity consumption per capita.

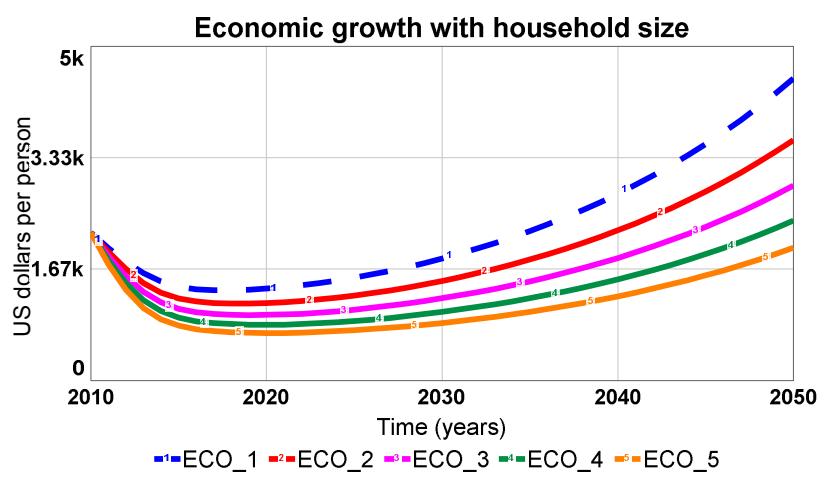

Figure 13. Economic growth varied by household size.

\subsection{Sensitivity Analysis for Electricity Tariff (SA-ET)}

Electricity Tariff (ET) was considered in this study as a determining variable of electricity demand. The SA for household size, performed in Sec. 3.3, was done based on a tariff ranging from $\$ 0.065 / \mathrm{KWh}$ to $\$ 0.085 / \mathrm{KWh}$. In line with all the previous runs, five scenarios were chosen. These scenarios, portrayed in Table 5, were incremented by 0.005 in a stepwise fashion in Stella.

Table 5. Sensitivity runs of Electricity tariff.

\begin{tabular}{ll}
\hline Run & Value \\
\hline 1 & 0.065 \\
2 & 0.070 \\
3 & 0.075 \\
4 & 0.080 \\
5 & 0.085 \\
\hline
\end{tabular}

\subsubsection{Effect of SA-ET on Electricity Demand (ED)}

Electricity tariff (ET) was a core variable considered in the simulation model. Impacts of ET on the model is shown in Figure 14. It can be seen that any increase in ED is perceived as a reduction in ET. The trend shown in ED ET1 has the 
steepest ramp with the lowest ET and a value of $\$ 0.065 / \mathrm{KWh}$. On the other extreme, ED_ET5 presents the lowest trend in all EDs.

However, simulation results showed no significant change in electricity consumption with varying ET, as shown in Figure 15. Although energy consumption is expected to increase with an increasing energy demanded, these anomalies could be caused by electricity insufficiencies in the NPS to meet demand. These tendencies are against normal trends in free market practices, i.e., a decrease in price leads to an increase in demand, which should in turn lead to an increase in consumption.

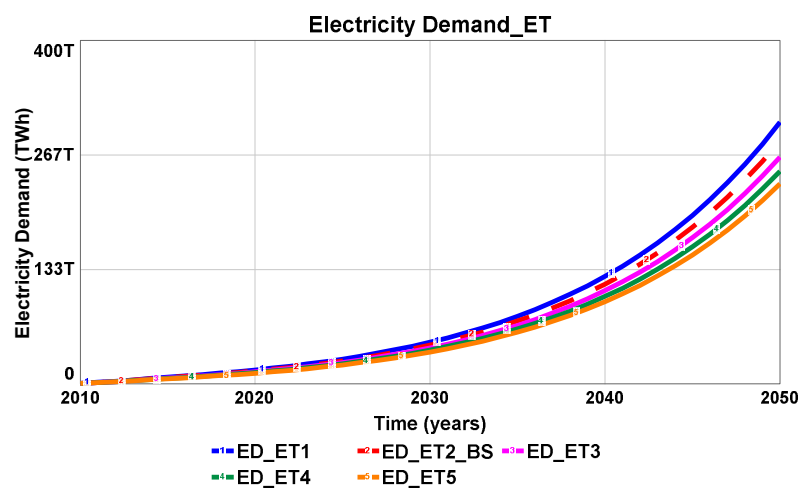

Figure 14. Electricity demand varied by Electricity Tariff.

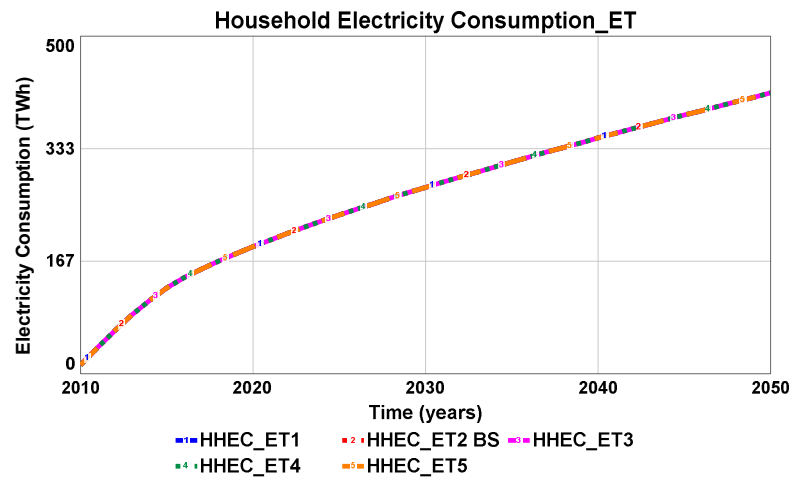

Figure 15. Electricity consumption varied by Electricity Tariff.

\subsubsection{Effect of SA-ET on Energy Saving Efficiency Goal}

An additional sensitivity test of efficient technologies to reach efficiency goals is presented in Figure 16. Time to reach efficiency goal is set to vary under a sensitivity test that ranges from 5 years, 10 years, to 15 years. The chosen sensitivity value is capable of capturing the influence of time delay in attaining efficiency goals. Figure 16 shows an earlier time to reach efficiency goal. A delay of $7.1 \%$ is experienced between 5 years and 10 years, while the gap 5 to 15 years reveals a delay of $9.4 \%$ in 2020 . Comparison of these two eventualities to the base scenario (Eff_2_BS) shows that Eff_1 has the highest trend in reaching electricity efficiency goal, While Eff_3 expresses the least trend. An information delay was employed to avoid circular reference, which has led to some action with a time delay.

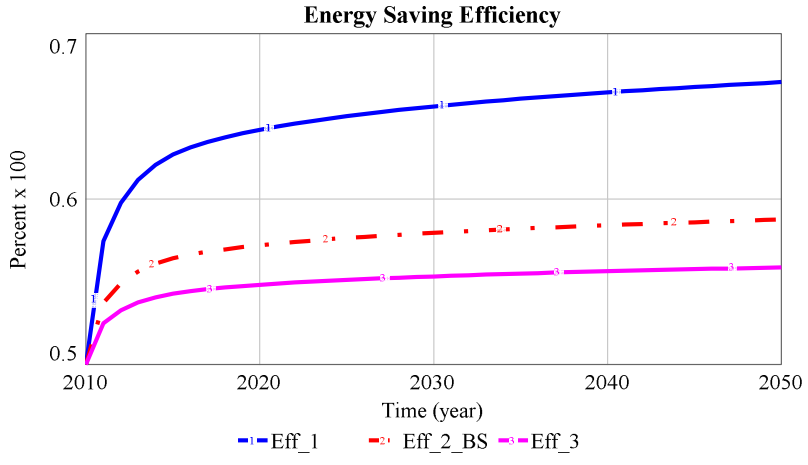

Figure 16. Energy saving efficiency with varied time to reach efficiency goal.

Furthermore, the study has considered a goal seeking character of consumption-efficiency. Change in the latter leads to a rapid increase during the initial period. The study also presents sensitivity analysis on electricity consumption. An additional aspect of the research extends by including social and economic factors, which may lead to changes of consumer behavior, i.e., tariffs versus motivation to save electricity regarding the use of more efficient appliances.

\section{Conclusions}

The study presents innovative approaches to effectively model residential electricity consumptions and its impacts on carbon dioxide emissions in Nigeria. The study has also considered factors and variables across the power sector, such as social, economic, and environmental aspects. Electricity savings, efficiency, and energy consumptions were largely influenced by the parameters considered in the study, viz., use of prepaid meters for electricity billing, use of efficient household appliances, and household size. These schemes largely influenced the rate at which residential electricity is saved. The innovations improved energy saving motivations among residents and were seen as the main drivers to efficient electricity consumption patterns. Conversely, electricity tariffs were found to be the major electricity demand factors. However, the study showed no direct correlations between electricity tariffs and energy consumption behaviors. This fact could be attributed to insufficiencies in electricity supply. Moreover, efficient electricity consumption, when achieved, is expected to reduce carbon emissions.

The study has successfully addressed issues of electricity metering and billing system, Employing system dynamics not only as a simulation and modeling tool, but also considering the dynamic behaviour of the Nigerian household electricity energy saving goals with their supporting information flow. Considerable across a number of different variables taking into account their basic structuring principles of feedback system, in order to help decision and policy makers through its effective policy structure depicted in the stock and flow structure of the model sub-system. Nevertheless, the method and approach of $\mathrm{HH}$ energy saving utilized in this study is innovative and as such, has not been fully considered in 
related studies as application of SD is currently limited within this context.

The results of this study can be improved and applied to other sectors that consumes electricity such as i) the commercial; ii) industrial and iii) agricultural sectors to further improve efficient usage of electricity. More focused studies on how to improve uncertainties will improve the credibility and application of the results. However, the present study has significantly advance understanding, method, theory and application of SD modeling in household energy saving, consumption behaviour and efficient household electric appliances considering usage of prepaid metering and billing system under various sensitivity analysis.

\section{Policy Recommendations}

For policy design, results might mean that (1) more attention should be paid to making prepaid meters of electricity billing readily available for energy consumers; (2) minimizing bureaucracy delays involved in acquiring the devices; (3) fast replacements of old inefficient appliances with more efficient ones should be legislated; (4) subsidized; and (5) pay more attention to supporting advancement in research and technology into energy saving appliances.

Finally, the dynamics of efficient electricity consumption were effectively captured, considering feedback loops and delays by employing system dynamics modeling approach. This approach showed huge capabilities of SD to effectively replicate complex behaviors and dynamics in the Nigerian power sector indicating possible action points.

\section{References}

[1] IEA, IRENA, UNSD, WB, WHO “Tracking SDG 7: The energy progress report," Washington, DC, 2019.

[2] World. Bank, "Electricity Transmission And Access Project," Republic Of Côte D' Ivoire, 2017.

[3] S. E. Céline Ramstein, Goran Dominioni, "State and Trends of Carbon Pricing 2019,” 2019.

[4] WEF, "Energy for Economic Growth Energy Vision Update $2012, " 2012$.

[5] EIA, "Annual Energy Outlook 2019 with projections to $2050, " 2019$.

[6] UNDP, World Energy Assessment: energy and the challenge of sustainability. The United Development Programme. New York, NY 10017, 2000.

[7] EIA, "Annual Energy Outlook 2018 with projections to 2050," Washington, DC, 2018.

[8] IRENA, "REmap 2030: A Renewable Energy Roadmap," IRENA, Abu Dhabi, 2014.

[9] J. Heinonen and S. Junnila, "Residential energy consumption patterns and the overall housing energy requirements of urban and rural households in Finland," Energy Build., vol. 76, pp.
295-303, 2014.

[10] A. S. Momodu, A. Addo, J. K. Akinbami, and Y. Mulugetta, "Low-carbon development strategy for the West African electricity system: preliminary assessment using System dynamics approach," Energy. Sustain. Soc., vol. 7, no. 11, pp. $1-23,2017$.

[11] U. C. Nwaneto, U. B. Akuru, P. I. Udenze, C. C. Awah, and O. I. Okoro, "Economic Implications of Renewable Energy Transition in Nigeria," 2018, no. September, pp. 1-9.

[12] I. Dyner, R. A. Smith, G. E. Peña, I. Dyner, R. A. Smith, and G. E. Pena, "System Dynamics Modelling for Residential Energy Efficiency Analysis and Management Published by: Palgrave Macmillan Journals on behalf of the Operational Research Society Stable URL: https://www.jstor.org/stable/2584613 Linked references are available,” J. Oper. Res. Soc., vol. 46, no. 10, pp. 1163-1173, 1995.

[13] S. Babajide, "A System Dynamics Model of the Nigerian Electricity System,” 2018 Adv. Sci. Eng. Technol. Int. Conf., pp. 1-5, 2018.

[14] NREEEP, "National Renewable Energy and Energy Approved by FEC for Ministry of Power Federal Republic of Nigeria," 2015.

[15] P. E. Orukpe and F. O. Agbontaen, "Prepaid Meter in Nigeria : The Story so Far and the Way Forward," Adv. Mater. Res., vol. 824, pp. 114-119, 2013.

[16] F. I. Abam and B. N. Nwankwojike, "Energy resource structure and on-going sustainable development policy in Nigeria : a review," Int. J. Environ. Eng., 2014.

[17] M. G. Oladokun and I. A. Odesola, "Household energy consumption and carbon emissions for sustainable cities - A critical review of modelling approaches," Int. J. Sustain. Built Environ., vol. 4, no. 2, pp. 231-247, 2015.

[18] I. Bajracharya and N. Bhattarai, "System Dynamics Modeling of Lighting Electricity Demand in the Urban Residential Sector of Nepal," J. Dev. Adm. Stud., vol. 23, no. (1-2), pp. 33-54, 2015.

[19] Y. Y. Feng, S. Q. Chen, and L. X. Zhang, "System dynamics modeling for urban energy consumption and CO 2 emissions : A case study of Beijing, China," Ecol. Modell., vol. 252, pp. 44-52, 2013 .

[20] E. N. Vincent and S. D. Yusuf, "Integrating Renewable Energy and Smart Grid Technology into the Nigerian Electricity Grid System," Smart Grid Renew. Energy, vol. 5, no. September, pp. 220-238, 2014.

[21] M. O. Dioha, "Modelling the Impact of Nigeria Household Energy Policies on Energy Consumption and $\mathrm{CO}_{2}$ Emissions," Eng. J., vol. 22, no. 6, pp. 1-20, 2019.

[22] G. Browne, P. Luis, and L. Weston, "The World Bank Annual Report 2019," Washington, DC, 2019.

[23] Federal Government of Nigeria, "Nigeria Vision 20: 2020 Abridged Version," 2010.

[24] A. Malama, P. Mudenda, A. Ng, and L. Makashini, "The Effects of the Introduction of Prepayment Meters on the Energy Usage Behaviour of Different Housing Consumer Groups in Kitwe," vol. 2, no. 3, pp. 237-259, 2014. 
[25] F. W. Geels, B. K. Sovacool, T. Schwanen, and S. Sorrell, "The Socio-Technical Dynamics of Low-Carbon Transitions," Joule, vol. 1, no. 3, pp. 463-479, 2017.

[26] J. K. Musango, A. C. Brent, and A. M. Bassi, "Technological Forecasting \& Social Change Modelling the transition towards a green economy in South Africa," Technol. Forecast. Soc. Chang., vol. 87, pp. 257-273, 2014.

[27] S. B. Nugroho et al., "The Effect of Prepaid Electricity System on Household Energy Consumption - the Case of Bogor, Indonesia," Procedia Eng., vol. 198, no. September 2016, pp. 642-653, 2017.

[28] P. N. K. Deenapanray and A. M. Bassi, "System Dynamics Modelling of the Power Sector in Mauritius," Environ. Clim. Technol., vol. 16, no. 1, pp. 20-35, 2015.

[29] L. Wen, L. Bai, and E. Zhang, "System dynamic modeling and scenario simulation on Beijing industrial carbon emissions," Environ. Eng. Res., vol. 21, no. 4, pp. 355-364, 2016.

[30] M. Gebremicael, H. Yuan, and K. Tomsovic, "Restructured West African Power Pool," pp. 1-4, 2009.

[31] A. S. Momodu and L. Kivuti-bitok, "System dynamic modelling of electricity planning and climate change in West Africa [version 2; referees: 1 approved, 2 approved with reservations] Referee Status" no. 0, pp. 1-21, 2018.

[32] Y. Moumouni, S. Ahmad, and R. J. Baker, "A system dynamics model for energy planning in Niger," Int. J. Energy Power Eng., vol. 3, no. 6, pp. 308-322, 2014.

[33] Sterman John. D, Business Dynamics: System Thinking and Modeling for a Complex World. McGraw-Hill, 2000.

[34] A. Beall, F. Fiedler, J. Boll, and B. Cosens, "Sustainable water resource management and participatory system dynamics.
Case study: Developing the palouse basin participatory model," Sustainability, vol. 3, no. 5, pp. 720-742, 2011.

[35] J. W. Forrester, "Some Basic Concepts in System Dynamics," pp. 1-17, 2009.

[36] J. W. Forrester, "System Dynamics, Systems Thinking, and Soft OR,” vol. 10, no. 2, pp. 1-14, 1992.

[37] C. Thanacha and A. Magzari, "Mathematics behind System Dynamics," Worcester Polytechnic Institute In, 2012.

[38] J. D. Sterman, Business Dynamics Systems Thinking and Modeling for a Complex World. Jeffrey J. Shelstad, 2000.

[39] J. W. Forrester and S. Albin, "Building a System Dynamics Model Part 1 : Conceptualization," 1997.

[40] L. F. Luna-reyes, "Model Conceptualization: a Critical Review Model Conceptualization : a Critical Review," no. 518, pp. 1-11.

[41] N. Cihat, G. Egilmez, and O. Tatari, "Towards greening the U.S. residential building stock : A system dynamics approach," Build. Environ., vol. 78, pp. 68-80, 2014.

[42] Iseesystems, "Creating CLDs," 2018. [Online]. Available: https://www.iseesystems.com/resources/help/v13/default.htm\#03-

BuildingModels/Causal_Loop_Diagrams/Creating_CLDs.htm ?Highlight=CLD. [Accessed: 09-Jan-2020].

[43] U. Bariss, G. Bazbauers, A. Blumberga, and D. Blumberga, "System Dynamics Modeling of Households ' Electricity Consumption and Cost-Income Ratio : a Case Study of Latvia," vol. 20, 2017.

[44] Y. Zheng, F. Han, Y. Tian, B. Wu, and Z. Lin, Addressing the Uncertainty in Modeling Watershed Nonpoint Source Pollution, 1st ed., vol. 26. (C) 2014 Elsevier B. V. All rights reserved., 2014. 